\title{
Clear-sky biases in satellite infrared estimates of upper tropospheric humidity and its trends
}

Article

Accepted Version

John, V.O., Holl, G., Allan, R., Buehler, S.A., Parker, D.E. and Soden, B.J. (2011) Clear-sky biases in satellite infrared estimates of upper tropospheric humidity and its trends. Journal of Geophysical Research, 116. D14108. ISSN 01480227 doi: https://doi.org/10.1029/2010JD015355 Available at https://centaur.reading.ac.uk/21843/

It is advisable to refer to the publisher's version if you intend to cite from the work. See Guidance on citing.

To link to this article DOI: http://dx.doi.org/10.1029/2010JD015355

Publisher: American Geophysical Union

All outputs in CentAUR are protected by Intellectual Property Rights law, including copyright law. Copyright and IPR is retained by the creators or other copyright holders. Terms and conditions for use of this material are defined in the End User Agreement.

www.reading.ac.uk/centaur 
Central Archive at the University of Reading

Reading's research outputs online 


\section{Clear-sky biases in satellite infrared estimates of upper tropospheric humidity and its trends}

Viju O. John ${ }^{1}$, Gerrit Holl ${ }^{2}$, Richard P. Allan ${ }^{3}$, Stefan A. Buehler ${ }^{2}$, David E.

Parker $^{1}$, Brian J. Soden ${ }^{4}$

Viju Oommen John, Met Office Hadley Centre, Exeter, UK, (viju.john@metoffice.gov.uk)

${ }^{1}$ Met office Hadley Centre, UK

${ }^{2}$ Luleå University of Technology, Kiruna,

Sweden

${ }^{3}$ Department of Meteorology, University

of Reading, UK

${ }^{4}$ Rosenstiel School of Marine and

Atmospheric Science, Uni. of Miami, USA 
Abstract. We use microwave retrievals of upper tropospheric humidity (UTH) to estimate the impact of clear-sky-only sampling by infrared instruments on the distribution, variability and trends in UTH. Our method isolates the impact of the clear-sky-only sampling, without convolving errors from other sources. On daily time scales IR-sampled UTH contains large data gaps in convectively active areas, with only about $20-30 \%$ of the tropics $\left(30^{\circ} \mathrm{S}-\right.$ $30^{\circ} \mathrm{N}$ ) being sampled. This results in a dry bias of about $-9 \% \mathrm{RH}$ in the areaweighted tropical daily UTH time series. On monthly scales, maximum clearsky bias (CSB) is up to $-30 \% \mathrm{RH}$ over convectively active areas. The magnitude of CSB shows significant correlations with UTH itself (-0.5) and also with the variability in UTH (-0.6). We also show that IR-sampled UTH time series have higher interannual variability and smaller trends compared to microwave sampling. We argue that a significant part of the smaller trend results from the contrasting influence of diurnal drift in the satellite measurements on the wet and dry regions of the tropics. 


\section{Introduction}

Water vapour in the upper troposphere is important for radiative and hydrological feedbacks in the climate system [e.g., Held and Soden, 2000]. Measurements of $6.7 \mu \mathrm{m}$ channel (Channel 12) radiance from the High Resolution Infrared Radiation Sounder (HIRS) instrument on National Oceanic and Atmospheric Administration (NOAA) polar orbiting satellites have provided a vital infrared (IR) record of upper tropospheric humidity (UTH, defined as the relative humidity in the upper troposphere weighted by the Jacobian of Channel 12) since 1979 [e.g., Soden and Bretherton, 1996]. HIRS UTH data have been used for a variety of purposes such as evaluating the humidity distribution [e.g., Soden and Bretherton, 1996], comparing with in situ measurements [Soden and Lanzante, 1996], studying the variability [Bates et al., 1996, 2001; McCarthy and Toumi, 2004], evaluating climate models [Bates and Jackson, 1997; Allan et al., 2003; Soden et al., 2005], and for estimating trends [Bates and Jackson, 2001; Soden et al., 2005]. These studies have used various versions of the clear-sky HIRS data set developed by the NOAA's National Climate Data Center (NOAA/NCDC). Since clouds are not transparent to IR radiation and the tropics contain extensive coverage of upper level clouds [e.g., Sassen et al., 2008], IR UTH retrievals require careful screening of cloud.

Cloud contamination of IR measurements can introduce a positive UTH bias [Soden and Lanzante, 1996]. However, more important is a dry bias or clear-sky bias (CSB) introduced by the preferential sampling of drier, lower UTH cloud-free scenes by the IR measurements [Lanzante and Gahrs, 2000]. This poses a challenge in comparing IR UTH data sets with consistently sampled clear-sky UTH simulated by climate models 
[Cess and Potter, 1987; Allan et al., 2003]. From a climate model, clear-sky diagnostics are calculated at any required time step by setting cloud fraction to zero in a radiative transfer model. However, IR satellite measurements of clear-sky radiances are not possible when there is a cloud at or above the dominant emitting layers of the atmosphere in the field of view of the satellite instrument. This issue was also raised in Buehler et al. [2008] when comparing IR UTH with other humidity data sets and is a general problem in the estimates of clear-sky fields from satellite infrared and visible measurements [Erlick and Ramaswamy, 2003; Allan et al., 2003; Allan and Ringer, 2003; Sohn et al., 2006; Sohn and Bennartz, 2008]. Lanzante and Gahrs [2000] reported a modest (a few percent of RH) CSB in satellite IR measurements although the analysis remains inconclusive due to limitations [e.g., Soden and Lanzante, 1996; Moradi et al., 2010] of the radiosonde observations.

Recently, Sohn et al. [2006] also estimated the dry bias in IR clear-sky UTH estimates using upper tropospheric water vapour (UTW, in $\mathrm{kg} \mathrm{m}^{-2}$ ) retrieved from the Special Sensor Microwave/Temperature-2 (SSM/T-2), seasonal mean atmospheric temperature and water vapour profiles from the NCEP [Kalnay et al., 1996] reanalysis, and cloud information from the International Satellite Cloud Climatology Project (ISCCP) data set. Through this indirect method, they estimated the dry bias to be $20-30 \% \mathrm{RH}$ in highly convective areas, a significantly higher value than the estimate of Lanzante and Gahrs [2000]. However, errors in UTW, ISCCP cloud products, and NCEP profiles are likely to have affected these results.

The aim of the present study is to isolate only the impact of clear-sky-only sampling and to avoid errors from other factors and data sets. Another motivation of this study is 
to explore the impacts of clear-sky-only sampling on the variability and trend of a UTH data set. Lanzante and Gahrs [2000] speculated IR satellite data may underestimate UTH trend in the tropics by a factor of 0.15. Allan et al. [2003] used climate model simulations to suggest that clear-sky sampling did not affect interannual variability significantly. However, so far in the literature, discussions on the impacts of clear-sky-only sampling are generally limited to the distribution of humidity.

To illustrate the potential influence of clear-sky sampling on trends and variability, we show time series of $400 \mathrm{hPa}$ relative humidity $(\mathrm{RH})$ anomalies, area-weighted over the tropical (30S-30N) all and clear areas, in the upper panel of Figure 1, using 20 years (1989-2008) of daily humidity and cloud cover data from the ERA-Interim reanalysis [Simmons et al., 2007]. Clear areas are identified here by grid boxes with less than $30 \%$ cloud cover. It is evident that the interannual variability and trend of the clear areas are significantly different from those for the whole tropics. This suggests that caution should be taken when analysing the IR UTH data, which samples only clear areas, to find out variability and trends in UTH and provides a further motivation for assessing the effect of clear-sky-only sampling on satellite IR UTH datasets.

Since late 1998, microwave (MW) instruments such as the Advanced Microwave Sounding Unit-B (AMSU-B) and the Microwave Humidity Sounder (MHS) have been flown together with HIRS. The instruments have similar spatial sampling characteristics (crosstrack scanning, with very similar viewing geometries) and the weighting function of one of the microwave channels $(183.31 \pm 1.00 \mathrm{GHz})$ is similar to that of HIRS Channel 12 , thus allowing for coincident UTH measurements. Microwave data are only contaminated by precipitating cold clouds: less than $5 \%$ of the data are discarded as cloud contami- 
nated, thus they provide an almost all-sky UTH dataset [e.g., Brogniez and Pierrehumbert, 2007]. The present study therefore provides a unique opportunity to estimate the impacts of clear-sky-only sampling in the IR UTH using MW UTH.

This article is organised as follows: Section 2 contains description of data sets used and analysis method, Section 3 discusses the results and Section 4 provides the summary and discussion.

\section{Data and Method}

\subsection{Study approach}

Buehler et al. [2008] estimated the impact of cloud-filtering on UTH from microwave measurements on monthly time scales to be less than $5 \% \mathrm{RH}$ in the tropics (see their Figure 4). They calculated the difference between UTH from using all pixels and UTH from only clear pixels. Note that "clear" for microwave is different from "clear" for infrared. UTH data calculated without cloud filtering have some values more than $100 \% \mathrm{RH}$ with respect to water due to cloud contamination. Therefore, estimates of Buehler et al. [2008] can be considered as the upper limit of the sampling bias in microwave UTH data and the true bias will be less than their estimate. Thus, the microwave estimate of UTH can be used to estimate the CSB in IR data, although CSB can be a few \%RH higher where precipitating cold clouds are present.

The basic idea of our study is to select those microwave scenes which would be considered cloud-free by HIRS, and compare this sub-sample to the cloud-cleared (as described in Section 2.5) AMSU-B/MHS data. In this way we can isolate the effect of the HIRS clearsky only sampling, while at the same time ignoring any other differences between the two sensor types (such as slightly different weighting functions of HIRS and AMSU-B/MHS, 
calibration errors, or RT model errors). Note that the HIRS data are only used to define sampling, the HIRS UTH data themselves are not used anywhere in this study.

We focus our study in the tropics $\left(30^{\circ} \mathrm{S}-30^{\circ} \mathrm{N}\right)$ as it is the most important area of the globe for water vapour feedback [Held and Soden, 2000].

\subsection{HIRS clear-sky brightness temperature}

We used clear-sky HIRS data from http://www.ncdc.noaa.gov/HObS [Shi and Bates, 2011] to identify pixels which were cloud-free according to the NCDC HIRS cloud clearance algorithm which is similar to Rossow and Garder [1993] and is as follows. Observed window channel brightness temperatures at $11.1 \mu \mathrm{m}$ are compared spatially and temporally to an estimated clear-sky value and rejected as cloudy if the observation is too cold. For obtaining clear-sky observations, the thresholds are chosen to remove all clouds at the expense of removing some clear-sky pixels. It should be noted that most of the climate analyses of UTH have been conducted using the NCDC HIRS data set (e.g., studies mentioned in Section 1). In this study we use "infrared (IR)" to denote the NCDC HIRS data.

\subsection{Microwave brightness temperature}

We obtained brightness temperatures from the Microwave Humidity Sensor (MHS, equivalent to AMSU-B) on the MetOpA satellite for 2008 and mapped them on to the HIRS resolution (Level 1d) using the ATOVS and AVHRR Processing Package [AAPP; Atkinson and Whyte, 2003]. The spatial resolution of the MHS measurements is about $16 \mathrm{~km}$ at nadir and for the HIRS/4 instrument is $10 \mathrm{~km}$ at nadir. Mapping the MHS to 
HIRS grid eliminates biases which could originate from different spatial resolutions of the instruments.

\subsection{UTH estimation from microwave data}

UTH can be estimated using the $183.31 \pm 1.00 \mathrm{GHz}$ microwave channel measuements of MHS (Channel 3). The weighting function of this channel is generally sensitive to the relative humidity of a wide atmospheric layer, approximately between 500 and $200 \mathrm{hPa}$. The weighting function can move up or down according to variations in total humidity content of the atmosphere which is not very large for a tropical atmosphere (see Buehler and John [2005] and Buehler et al. [2008] for a detailed discussion). According to Buehler and John [2005], there is a simple transformation of the brightness temperature of $183.31 \pm 1.00 \mathrm{GHz}$ channel $\left(\mathrm{T}_{\mathrm{B} 3}\right)$ to UTH as shown in the following equation:

$$
\ln (\mathrm{UTH})=a+b * \mathrm{~T}_{\mathrm{B} 3}
$$

where UTH is the relative humidity in the upper troposphere weighted with the channel's weighting function, and $a$ and $b$ are regression coefficients which are derived for each viewing angle of the instrument. More details on the retrieval methodology can be found in Buehler and John [2005]. UTH data are not affected by the limb effect because we use appropriate regression coefficients for each viewing angle [John et al., 2006]. The data set has been validated using high-quality radiosonde and satellite measurements [Buehler et al., 2004; John and Buehler, 2005; Buehler et al., 2008; Milz et al., 2009; Moradi et al., 2010]. Ideally, a comparison of these data to other (either observed or modelled) humidity data sets should be done by simulating the $183.31 \pm 1.00 \mathrm{GHz}$ radiances from the latter 
humidity data and then converting them to UTH as described above for a like-to-like comparison.

\subsection{Filtering cloud-contaminated microwave scenes}

Microwave radiances are affected by precipitating ice clouds so all the microwave radiances used in this study are filtered for clouds using a method developed by [Buehler et al., 2007] which works as follows. Firstly, Channel 3 of MHS is sensitive to higher altitudes of the troposphere than Channel $4(183.31 \pm 3.00 \mathrm{GHz})$. In clear-sky conditions, because of the lapse rate of air temperature, the brightness temperature of Channel $3\left(T_{B 3}\right)$ is colder than the brightness temperature of Channel $4\left(T_{B 4}\right)$. But ice clouds can make $T_{B 4}$ colder than $T_{B 3}$ because ice particle scattering is stronger at the sensitive altitudes of Channel 4 , owing to the higher average ice water content. When the cloud is very high and opaque, it can be considered like a low emissivity surface for both channels. TB3 is then warmer, because of the higher water vapour emission for this channel above this quasi-surface, which will increase both up- and down-welling radiation for this channel. Therefore, in the presence of an ice cloud $\Delta T_{B}=T_{B 4}-T_{B 3}$, which is positive in clear-sky conditions, becomes negative. Secondly, clouds also reduce the value of $T_{B 3}$ directly, so that a viewing angle dependent threshold $T_{t h r}(\theta)$ was utilized. In summary, the conditions for uncontaminated data are $\Delta T_{B}>0$ and $T_{B 3}>T_{t h r}(\theta)$. Data not fulfilling both conditions are considered cloud and/or rain contaminated. Values of $T_{t h r}$ for each viewing angle are given in Buehler et al. [2007]. The fraction of data detected as cloudy in the tropics varies from $3-5 \%$ depending on the sampling time of satellite. In this study the base data set used is the cloud-filtered AMSU-B/MHS data, i.e., cloud contaminated microwave scenes are discarded before analysing the data. 


\section{Results and discussion}

\subsection{Impact on UTH distribution}

In this section we discuss the impact of the clear-sky sampling of HIRS on the distribution of daily and monthly average UTH. Also, the dependence of the clear-sky bias (CSB) on the UTH is discussed. We iterate that the IR data are only used for sampling, the IR UTH data themselves are not used anywhere in this study. All of the UTH data in this study are retrieved from MW radiances. IR UTH refers to the UTH data which is created from MW UTH data by mimicking the HIRS instrument's clear-sky-only sampling.

\subsubsection{Daily data}

We created gridded $\left(1^{\circ} \mathrm{x} 1^{\circ}\right.$ longitude-latitude) data sets of MW UTH for both microwave-coverage and infrared-coverage sampling for each day of 2008. Examples of daily maps for January (upper panels) and July (lower panels) are shown in Figure 2. The left panels in Figure 2 show the microwave sampling and the right panels show infrared sampling. Microwave sampling is nearly uniform in the whole tropics, with only small data gaps which are mainly due to orbital gaps around $20^{\circ} \mathrm{N}$ and $20^{\circ} \mathrm{S}$, and the presence of deep convective or precipitating clouds. By contrast, infrared-coverage sampling in the right panels shows large gaps. In fact, the IR sampling is good only in the dry descending regions where the humidity is considerably lower than in the humid areas. Note also the intermittent presence of high UTH values in convective regions in IR sampling.

Studies, such as Xavier et al. [2010] which investigated the variability of UTH associated with the Indian summer monsoon using microwave data require daily UTH data. Such a study would have been impossible using infrared data because of persistent cloud cover 
over the monsoon region, but there is good coverage in microwave sampling over the Indian region in July.

The upper panel of Figure 3 shows the fraction of tropical sampling of infrared data for all available days in 2008. The sampling fraction is about $20 \%$, i.e., $80 \%$ of the data are rejected as cloud contaminated. There are also some days with the fraction as low as $12 \%$. It is noteworthy that there is no clear seasonal dependence in tropical average sampling fraction.

Area-weighted, tropical averaged UTH time series for microwave-coverage and infraredcoverage sampling are shown in the bottom panel of Figure 3. It shows that infraredcoverage tropical average UTH is always about $7 \% \mathrm{RH}$ lower than the microwave-coverage UTH. The yearly mean value of MW UTH is $31.2 \% \mathrm{RH}$ and for IR UTH it is $24.74 \% \mathrm{RH}$. The mean of the difference (IR-MW, not shown) time series is $-7.18 \pm 0.69 \% \mathrm{RH}$. The infrared-coverage time series is noisier than the microwave-coverage one owing to limited sampling (the standard deviation of IR time series is $1.24 \% \mathrm{RH}$ and that of $\mathrm{MW}$ time series is $1.05 \% \mathrm{RH})$. It is not clear how this will translate to variability on inter-annual and longer time scales. Changes in cloud detection algorithms can also introduce spurious changes in bias or variability. For example, cloud detection is mostly done on the basis of brightness temperature thresholds, so changes in brightness temperature of channels, due to instrument degradation etc., can impact the magnitude of clear sky bias. Though we can see a seasonal dependence in CSB for some regions when sampled in infrared-coverage, this does not lead to seasonal biases in the tropical averaged, infrared-coverage UTH time series. 
According to Buehler and John [2005] the retrieval bias of microwave UTH varies between $+2 \% \mathrm{RH}$ for low humidity values and $-4 \% \mathrm{RH}$ for high humidity values. This behaviour is typical of a linear regression method, in which the dry profiles are retrieved too moist and the moist profiles too dry. This occurs because components of the retrieval come from the prior information used and, in a linear regression scheme, the a priori profile is the mean of the data set used to compute the regression coefficients, and the $a$ priori error covariance is the covariance of the same data set [Eyre, 1987]. This means dry regions have a moist bias and wet regions have a dry bias, therefore the difference between them is smaller than that in reality. From Buehler and John [2005] (see their Figure 5), IR-sampled UTH values in dry regions have about $2 \% \mathrm{RH}$ moist bias, but this would not contribute to the difference in Figure 3, because the IR sampled UTH are also sampled by MW. However, high UTH values in the wet regions which are sampled only by MW have on average about $-2 \% \mathrm{RH}$ dry bias (although the maximum could be up to $-4 \% \mathrm{RH})$ and this has to be considered while estimating the clear-sky bias. This means that in Figure 3 the difference will be about $9 \% \mathrm{RH}$ instead of the $7 \% \mathrm{RH}$ depicted.

\subsubsection{Monthly data}

In general, monthly means of UTH are used for data analysis as well as for model evaluation [e.g., Bates et al., 1996, 2001; McCarthy and Toumi, 2004; Bates and Jackson, 1997; Soden et al., 2005], so we attempt to estimate the CSB based on monthly mean UTH values. This is one of the main differences compared to previous studies which could estimate CSB only on seasonal [Sohn et al., 2006] or longer time scales [Lanzante and Gahrs, 2000]. Figure 4 shows January and July monthly maps of microwave-coverage and infrared-coverage UTH. Monthly averages are obtained by collecting all the pixels 
available per grid box during the whole month and then computing the mean. One could also construct the monthly mean by first computing daily means and then averaging them. In the former method, a few clear days having many pixels (probably drier UTH) can outweigh a large number of humid days with few pixels. However, we found that the difference between the two averaging methods is only a few $\% \mathrm{RH}$ and has noisy spatial patterns.

UTH values are high along the inter tropical convergence zone (ITCZ) and over monsoon regions and low over the subsidence areas of the Hadley/Walker circulations. The distinction between humid and dry regions is better observed in the microwave-coverage compared to infrared-coverage. Seasonal migration of UTH patterns associated with the movements of ITCZ is also better represented in the microwave-coverage data.

The distributions are similar but with smaller UTH values in ascending areas for infrared-coverage, as expected (Figure 6, which will be discussed later, shows the differences directly). In some of the persistent convective regions, e.g., some areas in the Bay of Bengal during July, there is no infrared sampling for the whole month. Figure 5 shows the distribution of the number of pixels in each grid box for MW and IR-sampling. MW-sampling shows a nearly uniform distribution of pixels with a range of 200-400 pixels per grid point. The convective regions show fewer pixels, but still have more than sufficient pixels $(>200)$ to represent the distribution of monthly means. In IR sampling, convective and clear areas show a very large difference in the numbers of pixels with clear areas having 300 pixels and convective regions less than 40 pixels per grid point. There are also about $1 \%$ of grid points with no IR sampling for a whole month. 
The spatial distribution of CSB in infrared-coverage UTH is shown in Figure 6 for January and July. It is calculated as infrared-coverage minus microwave-coverage UTH. In regions of precipitating and deep convective clouds, microwave data also will have a small dry bias which according to Buehler et al. [2007] is about 2-3\%RH. However, this is negligible compared to the CSB in convective regions which is up to $-30 \% \mathrm{RH}$. CSB is larger than $-20 \% \mathrm{RH}$ at $1.3 \%$ and $0.4 \%$ of grid points for January and July, respectively. The maximum bias for both months is $-32 \% \mathrm{RH}$. As noted previously there are grid points with no IR data at all for a whole month. Maximum CSB, \% of grid points with missing data and CSB more than $-20 \% \mathrm{RH}$ for all months are given in Table 1. Maximum CSB values are in the range of $30-36 \% \mathrm{RH}$. There are 0.8 to $3.3 \%$ of grid boxes (ie., about 200 to 700 grid points out of 21600 grid points in the tropics) with no IR sampling for the entire month and 70-330 grid boxes with CSB larger than $-20 \% \mathrm{RH}$.

The main difference of these results compared to Lanzante and Gahrs [2000] is that we get coherent patterns of CSB by just using one month of data and without using robust statistical parameters. This is because statistical noise is reduced by the larger sample and by avoidance of no error contributions from spatio-temporal mis-matches and measurement methodology diferences in our comparison method. Another difference is the magnitude of CSB: they estimated the bias to be $5-10 \% \mathrm{RH}$ whereas our results show at least twice this magnitude in convective regions.

We have also analysed the entire \pm 60 latitude range and the results show CSB similar to the tropics over the storm tracks in the mid latitudes. An example for this is shown in Figure 7. The NCDC HIRS data are cloud cleared not only for high clouds, but also for all types of clouds including low level clouds which do not contaminate Channel 12 
measurements. Therefore the clear-sky bias is not only confined to the convectively active regions but also to low/mid level cloud regions (e.g., Eastern Pacific, north of maritime continent during January).

\subsection{Dependence of CSB on UTH and its variability}

We have seen in previous sections that the magnitude of CSB is associated with the presence of convection. Also, convection is the main source of humidity in the tropical upper troposphere [Soden, 2004]. To explore the relation between CSB and UTH, we did a correlation analysis using all grid point values for January and July monthly averages and the results are shown in the upper panels of Figure 8 (scatter density plots on which the contours show the fraction of data points outside the contour). In general, the magnitude of CSB increases with increasing UTH. The correlation is -0.48 for January and -0.52 for July. The slope of the linear fit is $-0.241 \pm 0.003 \% \mathrm{RH}$ per $\% \mathrm{RH}$ for January and $-0.182 \pm 0.002 \% \mathrm{RH}$ per \%RH for July.

However, there are grid points with high humidity but small CSB. This could be due advection of humidity to clear areas. For example, Xavier et al. [2010] reported that, though convection mainly happens in the Bay of Bengal during the active phases of the Indian monsoon, there are high values of UTH over cloud free areas of the Arabian sea, because the strong easterly jet advects humidity from over the Bay of Bengal. In this case over the Arabian sea CSB will be small even if high UTH values are present. Therefore the high noise in the correlation analysis for higher humidity values is expected.

Figure 9 shows the standard deviation of UTH values at each grid point for MW and IR-sampling. A very noticeable feature is the lower grid point variability in IR-sampled UTH on monthly scales. It is expected that the variability of humidity will be high in 
locations with medium UTH, for example, near the boundaries of dry and humid regions due to changing dynamical regimes on intra-seasonal time scales [Xavier et al., 2010]. Also, the minimum variability is expected to be at grid points with persistently either low or high UTH on monthly to seasonal time scales. Note that clear-sky-only sampling reduces variance in medium UTH areas by preferentially removing high UTH values. But in convective areas clear-sky only sampling may increase variance by removing most of the samples, leaving only a few high values and few low values (instead of many high values and a few low values and thus low variance).

The lower panels of Figure 8 illustrate a very good correlation between the clear-sky bias and the grid point standard deviation of MW-sampled UTH for January and July. The correlation is -0.6 for both months. Small variability in UTH will generally produce small CSB since all values, clear and cloudy, will have similar UTH. This may not apply where there is persistent cloud cover and high UTH but a few clear events with low UTH, however. Larger variability in UTH gives the potential for large CSB providing that there is a correlation between UTH and mid to upper level cloudiness.

\subsection{Impact on inter-annual variability and trend}

Lanzante and Gahrs [2000] used the association between the UTH and the CSB to infer the temporal variability in the CSB. They speculated that the IR UTH in the tropics will underestimate the magnitude of either a positive or a negative trend, because if UTH increases in the tropics, it will lead to more cloudy days which results in CSB increasing with time. Conversely, if UTH decreases in the tropics, it will lead to fewer cloudy days which results in CSB deceasing with time. They estimated that the underestimation is by a factor of 0.15 . 
In Section 1 we discussed this issue using ERA-Interim $400 \mathrm{hPa}$ relative humidity and cloud cover data. It was shown that inter-annual variability and trend are significantly different for the clear and whole tropics (see Figure 1). UTH for clear areas shows a larger decreasing trend $(-1.50 \pm 0.10 \% \mathrm{RH}$ per decade) compared to the entire tropics $(-1.08 \pm 0.10 \% \mathrm{RH}$ per decade) which is at odds with the speculations of Lanzante and Gahrs [2000]. The bottom panel of Figure 1 shows the clear fraction of the tropics which indicate a small, but statistically significant decrease $(-0.5 \pm 0.13 \%$ per decade $)$ in the area of clear regions in tropics in the ERA-Interim reanalysis.

Though the microwave data are available only for about 10 years, we make an attempt to see how clear-sky-only sampling affects variability and trend in the actual UTH time series using data from AMSU-B on-board NOAA-15. The data are available since 1999. The HIRS instrument on NOAA-15 is HIRS/3 whose pixels have a spatial resolution of $18.9 \mathrm{~km}$ at nadir which is similar to the AMSU-B $(16 \mathrm{~km})$. To find the AMSU-B pixel closest to a HIRS clear-sky pixel, we have used the collocation method described in Holl et al. [2010]. Firstly, for each HIRS clear-sky pixel, we collected all AMSU-B pixels with a centrepoint of at most $30 \mathrm{~km}$ from the HIRS centrepoint. Then we select only the closest AMSU-B pixel thus found. In this way, we get a one-to-one mapping between HIRS clear-sky and AMSU-B, where the distances between the centrepoints are mostly between 0 and $15 \mathrm{~km}$, with some cases of distances between 15 and $30 \mathrm{~km}$ (corresponding to HIRS pixels outermost on the scan line where the pixel size increases to almost three times the nadir value). The time difference between the measurements is always negligibly small.

Figure 10 shows the area-weighted, tropical, daily, UTH anomaly time series. The standard deviations of IR- and MW-sampled time series are $1.05 \% \mathrm{RH}$ and $0.85 \% \mathrm{RH}$, 
respectively. This excess noise of for IR-sampling is comparable to that of the IR time series in Figure 3. The linear trends in the IR and MW-sampled time series are $-0.67 \pm 0.22$ and $-1.10 \pm 0.17 \% \mathrm{RH}$ per decade, respectively which means a smaller trend in clearsky-only sampling. This is at odds with the ERA Interim results shown in Figure 1, but appears consistent with the speculation of Lanzante and Gahrs [2000]. The error estimate of the linear trend was calculated by taking into account the autocorrelation of the time series as described in Santer et al. [2000]. We also calculated the trend in the difference time series (IR-sampling minus MW-sampling) which is is statistically significant at $0.43 \pm 0.14 \% \mathrm{RH}$ per decade.

It is plausible that the difference in the IR and MW trend does not fully relate to a real difference in UTH trends between the wet and dry regions as proposed by Lanzante and Gahrs [2000]. A likely explanation for the trend difference in this case is that satellite orbit drift causes aliasing of the diurnal cycle of UTH to preferentially affect the moist regions of the tropics. The orbit of NOAA-15 has drifted about 3 hours since 1998. The equator crossing time of NOAA-15 was 7:30 AM/PM in 1998 and is 4:30 AM/PM in 2010. This drift causes observed UTH to decrease for the ascending node (PM) and increase at a slower rate for the descending (AM) node according to Chung et al. [2007]. However, note that the diurnal cycle estimated by Chung et al. [2007] was only for METEOSAT-8 domain using IR UTH data and this may not be representative for the whole tropics. Separate analysis of NOAA-15 UTH data for ascending and descending nodes revealed a small decreasing trend for the descending node and a much larger decreasing trend for the ascending node (not shown). This suggests the diurnal cycle from orbit drift is affecting the overall trend although decreasing trends for both nodes may indicate other factors 
such as instrument degradation contributing to the overall trend. The aliasing will have been greater in the MW-sampling time series because it better samples the moist regions of the tropics where the diurnal cycle of UTH is greater. Correcting for aliasing of the diurnal cycle is a major task which we are pursuing.

It is not clear why the trend result is opposite for reanalysis, although the latter is not generally good at reproducing observed trends in the hydrological cycle [Bengtsson et al., 2004; John et al., 2009]. The trends in real data and reanalysis for clear areas are statistically similar. The satellite observations assimilated in the reanalysis over cloudy regions or errors arising from assimilating cloud affected radiances may be the reason for the unrealistic trend over wet regions in the reanalysis.

\section{Summary and discussion}

We have presented a unique method of estimating the impact of clear-sky-only sampling on the HIRS estimates of upper tropospheric humidity. The uniqueness of this study is its method which isolates only the sampling effects which is a clear advantage over previous studies. Previous studies have used radiosonde data, cloud and reanalysis information to deduce the impacts but at the cost of propagating errors in these data sets into the estimated impacts.

Our method uses co-flying infrared and microwave sensors on the same satellite. Microwave data are affected only by deep convective precipitating clouds, so they provide an almost all-sky estimate of UTH. We use clear sky infrared pixels provided by the NCDC data set to sub-sample the microwave data to simulate the infrared sampling of UTH. Thus, we do not use IR-measured UTH. If we had used IR-measured UTH, it would have introduced errors due to different sensitivities of IR and MW channels to humidity 
changes. We also mapped the microwave data to IR resolution using AAPP, thus reducing errors arising from different spatial resolution. Our method also eliminates errors caused by differing measurement times. Because these features of our method reduce the statistical noise we do not need a longer time period average or robust statistical parameters to obtain stable results.

Daily IR-sampled UTH data sample only the dry descending regions in the tropics, thus not giving any information on the upper tropospheric humidity in moisture-source areas. Daily, area-weighted, tropical averaged, IR-sampled UTH is always about $9 \% \mathrm{RH}$ lower than the MW-sampled UTH. Time series of IR and MW-sampled UTH were analysed for a year, but no seasonal variations in bias for tropical averaged time series are evident which is consistent with Allan et al. [2003].

IR-sampled monthly mean UTH data show excessively indistinct boundaries between ascending and descending regions. There are some areas in the tropics with no infrared coverage for an entire month. We estimated coherent patterns of clear-sky bias (CSB), which is the IR-sampled UTH minus MW-sampled UTH, on monthly time scales. Over some convective regions the CSB is as large as $-30 \% \mathrm{RH}$ which is about a $50 \%$ relative bias in UTH. Seasonal migration of CSB is also seen due to the movement of the tropical convergence zone. The bias is correlated not only with UTH values but also with UTH variability; the larger the variability the higher the bias. Inter-annual variability of tropical UTH time series is higher for IR-sampled UTH owing to larger spatial noise arising from limited sampling.

The implication of clear-sky-only sampling by infrared measurements for longwave cloud radiative forcing comparisons between models and satellite data has been discussed and 
documented [Cess and Potter, 1987; Allan and Ringer, 2003; Sohn et al., 2006; Sohn and Bennartz, 2008; Sohn et al., 2010]. The major contribution to the model-observation inconsistency in longwave cloud radiative forcing originates from upper tropospheric humidity [e.g., Sohn and Bennartz, 2008]. The large clear-sky bias in UTH corresponds to about $15 \mathrm{Wm}^{-2}$ bias in satellite estimates of cloud radiative forcing.

The clear-sky HIRS measurements are sampling meteorologically unusual situations of cloud free conditions, so they only represent a limited aspect of the climate system. Therefore, there is the potential for misinterpretation of feedbacks and variability in the climate system if this is not accounted for.

There is a small decreasing trend in the tropical UTH in the reanalysis and in AMSUB estimated UTH. But the impact of clear-sky-only sampling on the UTH trend has shown opposite results for reanalysis data and AMSU-B data. In the ERA Interim data the decreasing trend is larger in clear areas compared to the whole tropics, but it is the other way around for AMSU-B data. AMSU-B results are in line with the speculation of Lanzante and Gahrs [2000] that the clear-sky-only sampling will underestimate any trend in the UTH. However, it is plausible that a large part of UTH trend in AMSU-B data relates to diurnal cycle aliasing due to satellite orbital drift rather than a real trend. The MW-sampling is more sensitive to this as the diurnal cycle of UTH is larger in the moist regions which are not sampled by the IR method. Therefore the difference in trend for MW and IR sampling time series is not entirely due to the clear-sky-only sampling.

One might argue that it is not necessary to clear all clouds, but only mid- and highlevel clouds, when creating a UTH data set using HIRS Channel 12 measurements. We agree with this, but there is no HIRS data set with such cloud clearance that is readily 
available for climate analysis. In fact, the only HIRS data set available is the NCDC clear-sky radiance data set. Brogniez et al. [2006] have created a clear-sky radiance data set of METEOSAT $6.3 \mu \mathrm{m}$ channel radiances by clearing only high/middle clouds by using ISCCP cloud properties. This significantly enhanced the sampling mainly in the subtropical subsidence regions. However, the HIRS Channel 12 is sensitive to even thin cirrus clouds which cover a significant area in the tropics [Wylie et al., 2005; Sassen et al., 2008, 2009]. Also, some studies, for example, Jackson and Bates [2001], demonstrated the use of HIRS temperature sounding channels to improve the UTH retrieval algorithm. These temperature channels (HIRS Channels 4 and 6) are sensitive to upper and lower tropospheric temperatures, so they account for the tropospheric lapse rate. However, their method demands a completely clear-sky satellite radiances. Despite this, it would be useful to have a HIRS Channel 12 radiance data set with only high and mid level clouds cleared, cloud top heights being determined from AVHRR measurements.

Acknowledgments. VOJ and DEP were supported by the U.K. Joint DECC and DEFRA Integrated Climate Programme - GA01101. VOJ was also supported by UK JWCRP. RPA's contribution was supported by the UK National Centre for Earth Observation (NCEO) and National Centre for Atmospheric Sciences (NCAS). BJS's contribution was supported by the NOAA/Climate Program Office. This work contributes to COST Action ES604-Water Vapour in the Climate System (WaVaCS). Thanks to Lisa Neclos of the NOAA CLASS for recent and current MHS, AMSU-B and HIRS data, Lei Shi, NOAA/NCDC for the HIRS clear-sky data set and Fraser Lott for the MetOp archive. We thank John Eyre, Roger Saunders, and Ajil Kottayil for their valuable comments on the manuscript. 


\section{References}

Allan, R. P., and M. A. Ringer (2003), Inconsistencies between satellite estimates of longwave cloud forcing and dynamical fields from reanalysis, Geophys. Res. Lett., 30(9), doi:10.1029/2003GL017019.

Allan, R. P., M. A. Ringer, and A. Slingo (2003), Evaluation of moisture in the Hadley Centre climate model using simulations of HIRS water vapour channel radiances, $Q . J$. R. Meteorol. Soc., 129, 3371-3389.

Atkinson, N. C., and K. W. Whyte (2003), Further development of the ATOVS and AVHRR processing package (AAPP), including an initial assessment of EARS radiances, in Proceedings of the Thirteenth International TOVS Study Conference, edited by R. Saunders and T. Achtor, pp. 444-451, International ATOVS Working Group, Sainte-Adele, Quebec, Canada.

Bates, J. J., and D. L. Jackson (1997), A comparison of water vapor observations with AMIP I simulations, J. Geophys. Res., 102(D18), 21,837-21,852.

Bates, J. J., and D. L. Jackson (2001), Trends in upper-tropospheric humidity, Geophys. Res. Lett., $28(9)$, 1695-1698.

Bates, J. J., X. Wu, and D. L. Jackson (1996), Interannual variability of upper-troposphere water vapor band brightness temperature, J. Climate, 9, 427-438.

Bates, J. J., D. L. Jackson, F.-B. Breon, and Z. D. Bergen (2001), Variability of tropical upper tropospheric humidity 1979-1998, J. Geophys. Res., 106(D23), 32,271-32,281.

Bengtsson, L., S. Hagemann, and K. I. Hodges (2004), Can climate trends be calculated from reanalysis data?, J. Geophys. Res., 109, D11111, doi:10.1029/2004JD004536. 
Brogniez, H., and R. T. Pierrehumbert (2007), Intercomparison of tropical tropospheric humidity in gcms with AMSU-B water vapor data, Geophys. Res. Lett., 34, L17812, doi:10.1029/2006GL029118.

Brogniez, H., R. Roca, and L. Picon (2006), A clear sky radiances archive from METEOSAT "water vapor" observations, J. Geophys. Res., 111, D21109, doi:10.1029/ 2006JD007238.

Buehler, S. A., and V. O. John (2005), A simple method to relate microwave radiances to upper tropospheric humidity, J. Geophys. Res., 110, D02110, doi:10.1029/ 2004JD005111.

Buehler, S. A., M. Kuvatov, V. O. John, U. Leiterer, and H. Dier (2004), Comparison of microwave satellite humidity data and radiosonde profiles: A case study, J. Geophys. Res., 109, D13103, doi:10.1029/2004JD004605.

Buehler, S. A., M. Kuvatov, T. R. Sreerekha, V. O. John, B. Rydberg, P. Eriksson, and J. Notholt (2007), A cloud filtering method for microwave upper tropospheric humidity measurements, Atmos. Chem. Phys., 7(21), 5531-5542.

Buehler, S. A., M. Kuvatov, V. O. John, M. Milz, B. J. Soden, D. L. Jackson, and J. Notholt (2008), An upper tropospheric humidity data set from operational satellite microwave data, J. Geophys. Res., 113, D14110, doi:10.1029/2007JD009314.

Cess, R. D., and G. L. Potter (1987), Exploratory studies of cloud radiative forcing with a general circulation model, Tellus, Ser. A, 39, 460-473.

Chung, E. S., B. J. Sohn, J. Schmetz, and M. Koenig (2007), Diurnal variation of upper tropospheric humidity and its relations to convective activities over tropical Africa, Atmos. Chem. Phys., 7(10), 2489-2502. 
Erlick, C., and V. Ramaswamy (2003), Note on the definition of clear sky in calculations of shortwave cloud forcing, J. Geophys. Res., 108(D5), doi:10.1029/2002JD002990.

Eyre, J. R. (1987), On systematic errors in satellite sounding products and their climatological mean values, Q. J. R. Meteorol. Soc., 113, 279-292.

Held, I. M., and B. J. Soden (2000), Water vapor feedback and global warming, Annu. Rev. Energy Environ., 25, 441-475.

Holl, G., S. A. Buehler, B. Rydberg, and C. Jiménez (2010), Collocating satellite-based radar and radiometer measurements - methodology and usage examples, Atmos. Meas. Tech., 3(3), 693-708, doi:10.5194/amt-3-693-2010.

Jackson, D. L., and J. J. Bates (2001), Upper tropospheric humidity algorithm assessment, JGR, 106, 32,259-32,270.

John, V. O., and S. A. Buehler (2005), Comparison of microwave satellite humidity data and radiosonde profiles: A survey of European stations, Atmos. Chem. Phys., 5, 18431853, sRef-ID:1680-7324/acp/2005-5-1843.

John, V. O., S. A. Buehler, and N. Courcoux (2006), A cautionary note on the use of gaussian statistics in satellite based UTH climatologies, IEEE Geosci. R. S. Le., 3(1), 130-134, doi:10.1109/LGRS.2005.859350.

John, V. O., R. P. Allan, and B. J. Soden (2009), How robust are observed and simulated precipitation responses to tropical ocean warming?, Geophys. Res. Lett., 36, L14702, doi:10.1029/2009GL038276.

Kalnay, E., et al. (1996), The NCEP/NCAR 40-year reanalysis project, Bull. Amer. Met. Soc., $77,437-471$. 
Lanzante, J. R., and G. E. Gahrs (2000), The "clear-sky bias" of TOVS upper-tropospheric humidity, J. Climate, 13, 4034-4041.

McCarthy, M. P., and R. Toumi (2004), Observed inter-annual variability of tropical troposphere relative humidity, J. Climate, 17(16), 3181-3191.

Milz, M., S. A. Buehler, and V. O. John (2009), Comparison of AIRS and AMSU-B monthly mean estimates of upper tropopsheric humidity, Geophys. Res. Lett., doi:10. 1029/2008GL037068, in press.

Moradi, I., S. A. Buehler, V. O. John, and S. Eliasson (2010), Comparing upper tropospheric humidity data from microwave satellite instruments and tropical radiosondes, J. Geophys. Res., 115, D24310, doi:10.1029/2010JD013962.

Rossow, W. B., and L. C. Garder (1993), Cloud detection using satellite measurements of infrared and visible radiances for isccp, J. Climate, 6, 2341-2369.

Santer, B. D., T. M. L. Wigley, J. S. Boyle, D. J. Gaffen, J. J. Hnilo, D. Nychka, D. E. Parker, and K. E. Taylor (2000), Statistical significance of trends and trend differences in layer-average atmospheric temperature time series, J. Geophys. Res., 105(D6), 73377356.

Sassen, K., Z. Wang, and D. Liu (2008), Global distribution of cirrus clouds from cloudsat/cloud-aerosol lidar and infrared pathfinder satellite observations, J. Geophys. Res., 113, D00A12, doi:10.1029/2008JD009972.

Sassen, K., Z. Wang, and D. Liu (2009), Cirrus clouds and deep convection in the tropics: Insights from CALIPSO and CloudSat, J. Geophys. Res., 114, D00H06, doi:10.1029/ 2009JD011916. 
Shi, L., and J. J. Bates (2011), Three decades of intersatellite calibrated hirs upper tropospheric water vapor, J. Geophys. Res., D04108, doi:10.1029/2010JD014847.

Simmons, A. J., S. Uppala, D. Dee, and S. Kobayashi (2007), ERAInterim: New ECMWF reanalysis products from 1989 onwards, Tech. Rep. 110, ECMWF Newsl.

Soden, B. J. (2004), The impact of tropical convection and cirrus on upper tropospheric humidity: A lagrangian analysis of satellite measurements, Geophys. Res. Lett., 31, L20104, doi:10.1029/2004GL020980.

Soden, B. J., and F. P. Bretherton (1996), Interpretation of TOVS water vapor radiances in terms of layer-average relative humidities: Method and climatology for the upper, middle, and lower troposphere, J. Geophys. Res., 101(D5), 9333-9343, doi:10.1029/ 96JD00280.

Soden, B. J., and J. R. Lanzante (1996), An assessment of satellite and radiosonde climatologies of upper-tropospheric water vapor, J. Climate, 9, 1235-1250.

Soden, B. J., D. L. Jackson, V. Ramaswamy, M. D. Schwarzkopf, and X. Huang (2005), The radiative signature of upper tropospheric moistening, Science, 310, 841-844.

Sohn, B.-J., and R. Bennartz (2008), Contribution of water vapor to observational estimates of longwave cloud radiative forcing, J. Geophys. Res., 113, D20107, doi: 10.1029/2008JD010053.

Sohn, B.-J., J. Schmetz, R. Stuhlmann, and J.-Y. Lee (2006), Dry bias in satellite-derived water vapor and its contribution to longwave cloud radiative forcing, J. Climate, 19, $5570-5580$.

Sohn, B. J., T. Nakajima, M. Satoh, and H. S. Jang (2010), Impact of different difinitions of clear-sky flux on the determination of longwave cloud radiative forcing: NICAM simu- 
lation results, Atmos. Chem. Phys., 10, 11,641-11,646, doi:10.5194/acp-10-11641-2010.

Wylie, D., D. L. Jackson, W. P. Menzel, and J. J. Bates (2005), Trends in global cloud cover in two decades of hirs observations, J. Climate, 18, 3021-3031.

Xavier, P. K., V. O. John, S. A. Buehler, R. S. Ajayamohan, and S. Sijikumar (2010), Variability of indian summer monsoon in a new upper tropospheric humidity data set, Geophys. Res. Lett., 37, L05705, doi:10.1029/2009GL041861. 
Figure 1. The upper panel shows area-weighted, tropical, $400 \mathrm{hPa}$ relative humidity $(\mathrm{RH})$ anomaly time series of the ERA-Interim reanalysis. Daily data are used and a 30 day smoothing is applied for clarity. Clear areas represent grid points where the total cloud clover from the reanalysis is less than $30 \%$. The slopes of linear trends are $-1.08 \pm 0.10$, and $-1.50 \pm 0.10 \% \mathrm{RH}$ per decade for all and clear areas, respectively. The clear minus all time series (not shown) has a linear trend of $-0.43 \pm 0.07 \% \mathrm{RH}$ per decade. Error estimate of the linear trend is calculated by taking into account the autocorrelation of the time series as described in Santer et al. [2000]. The lower panel shows the clear fraction of the tropics. A linear fit which has a slope of $-0.50 \pm 0.13 \%$ per decade is also shown.

Figure 2. Examples of gridded daily UTH (in \%RH) for January and July for MW and IR sampling (see Section 2 for details on sampling). Note that the data themselves are microwave in all cases, only the sampling differs. In the IR maps, large areas appear white, because they are cloudy. 
Figure 3. The upper panel shows the IR sampling fraction. Lower panel shows the area-weighted average (tropics, $30 \mathrm{~S}$ to $30 \mathrm{~N}$ ) of UTH calculated from gridded daily fields (Figure 2) for all available days of 2008. The black line represents MW-sampling and the red line represents IR sampling.

Figure 4. Mean of UTH at each grid point for all available UTH values in a month. The upper panels are for January and the lower panels are for July. The left panels are for microwave sampling and the right panels for infrared sampling.

Figure 5. Total number of pixels in each grid box for a month. The upper panels are for January and the lower panels are for July. The left panels are for microwave sampling and the right panels for infrared sampling.

Figure 6. Clear-sky bias (CSB, which is the difference between IR-sampled and MWsampled UTH) in \%RH for (left) January and (right) July.

Figure 7. Clear sky bias (difference between IR-sampled and MW-sampled UTH) in \% RH for July for tropics and midlatitudes. 
Figure 8. Scatter density plots showing the dependence of clear-sky bias on UTH and its variability. Upper panels show dependence of tropical clear-sky bias on microwave sampled UTH and lower panels show its dependence on grid point standard deviation of microwave sampled UTH for (left) January and (right) July. Coloured contours show the fraction of data points outside each contour. Black is 0.01 , green is 0.1 , blue is 0.3 and red is 0.5 .

Figure 9. The standard deviation of UTH (in \%RH) at each grid point for all available pixels in a month. The upper panels are for January and the lower panels are for July. The left panels are for microwave sampling and the right panels for infrared sampling.

Figure 10. Time series of tropical, area-weighted, UTH anomalies for (red) microwave sampling and (black) infrared sampling using NOAA-15 AMSU-B satellite data. A 30 days smoothing is applied. Straight lines show a linear trend in the data. It should be noted that the time series is not corrected for diurnal cycle aliasing due to satellite orbital drift which is identified as the main reason for the spurious trend seen in the time series. Please see the text for details. 
Table 1. Statistics of clear-sky bias (CSB) for all months in 2008. "Miss" denotes \% of grid points with missing values due to no IR sampling for the entire month. ">20" denotes \% of grid points where CSB is higher than $20 \% \mathrm{RH}$. There are 21600 grid points in the tropics.

\begin{tabular}{rrrrrrrrrrrrrr}
\hline & Jan & Feb & Mar & Apr & May & Jun & Jul & Aug & Sep & Oct & Nov & Dec \\
\cline { 1 - 7 } Max & -31.87 & -36.20 & -36.27 & -33.94 & -30.27 & -31.27 & -32.25 & -29.88 & -31.08 & -27.14 & -32.50 & -33.84 \\
Miss & 1.49 & 3.32 & 2.07 & 1.23 & 1.05 & 1.54 & 1.77 & 0.76 & 1.19 & 0.98 & 1.44 & 1.91 \\
$>20$ & 1.31 & 1.18 & 0.67 & 0.94 & 0.88 & 0.48 & 0.41 & 0.32 & 0.50 & 0.58 & 0.79 & 1.53
\end{tabular}




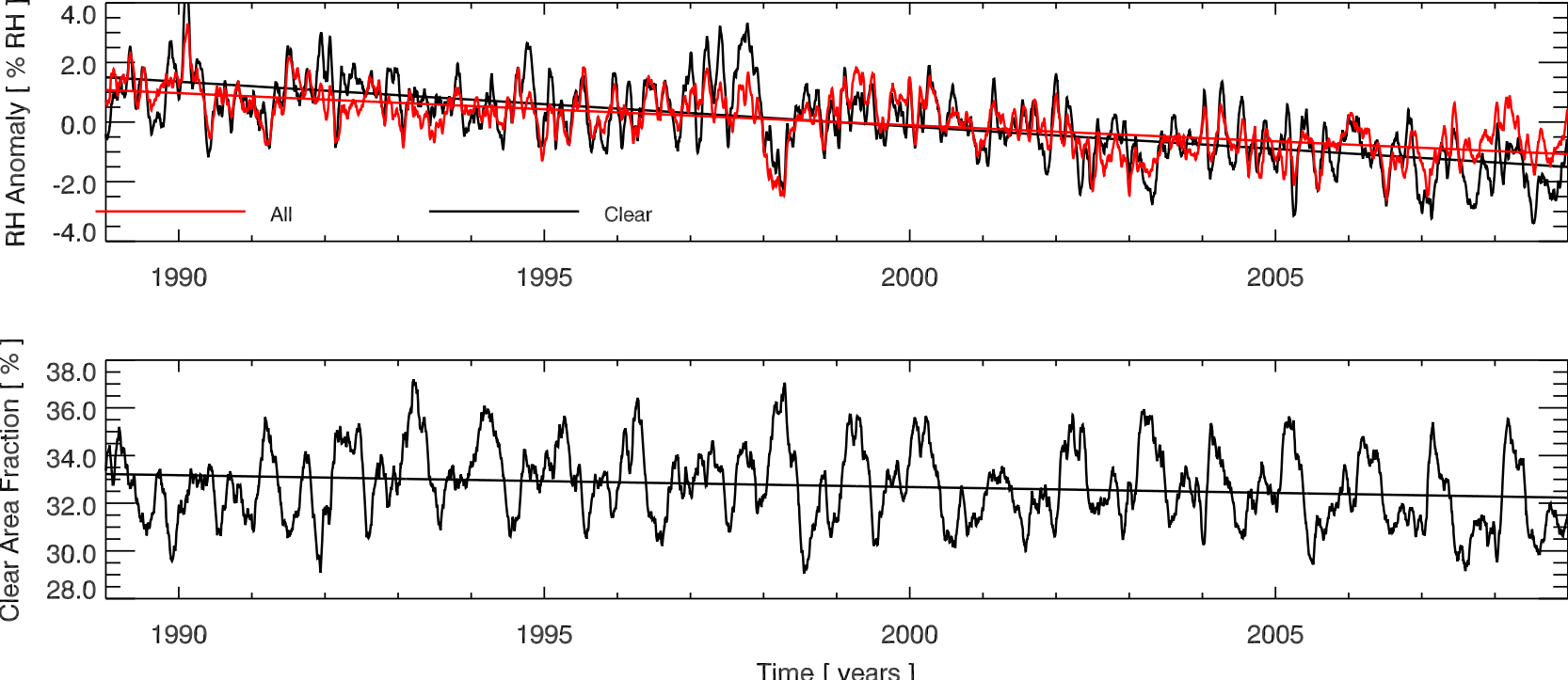




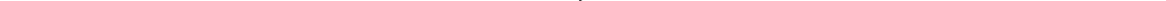



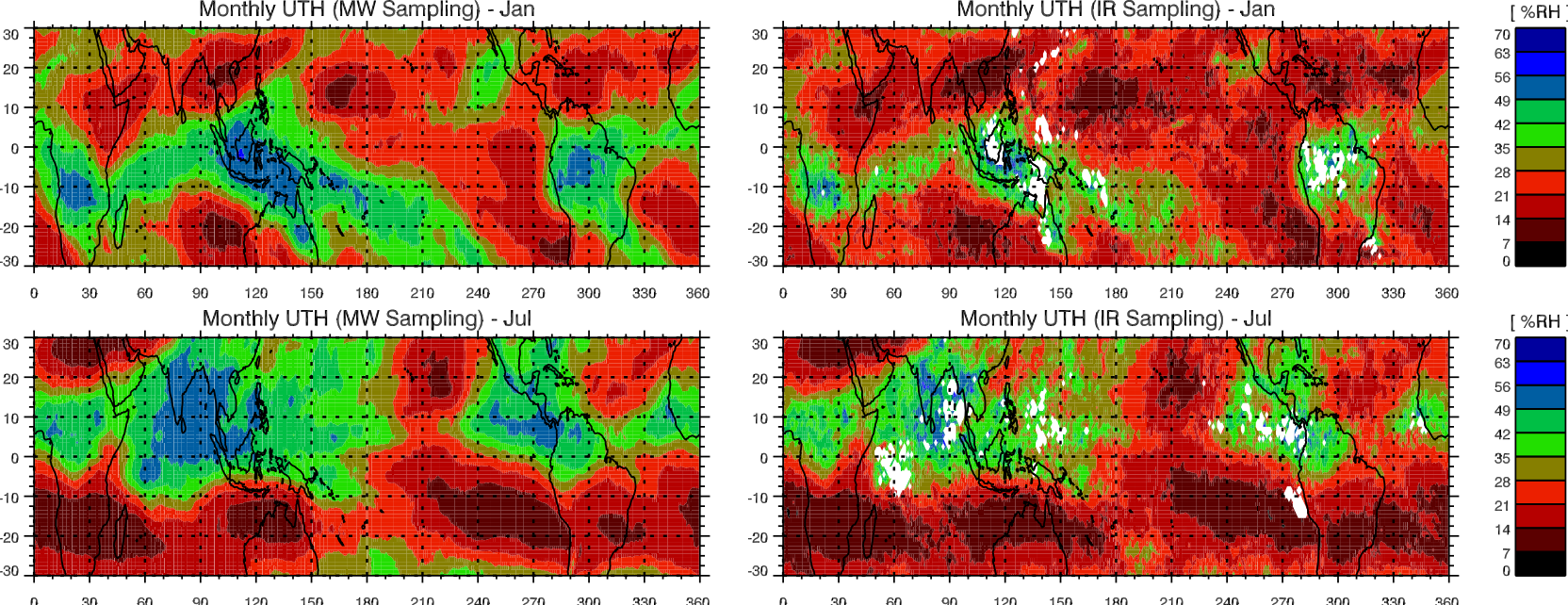

[\%RH ]

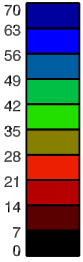


Clear-sky bias - Jul

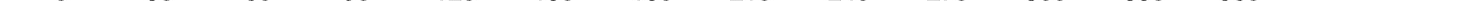


Jan
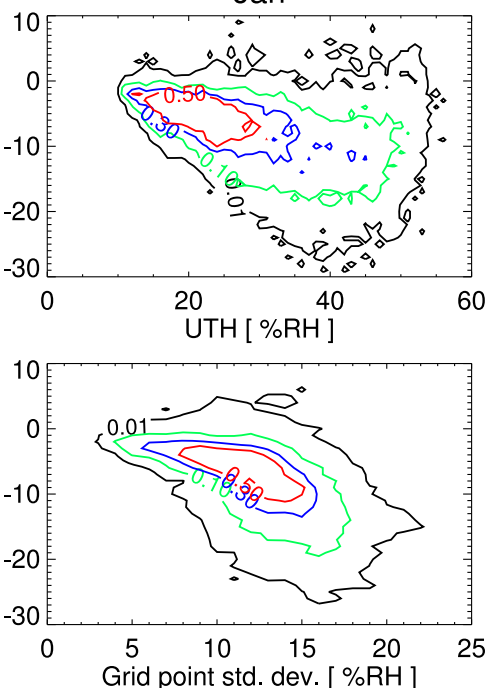
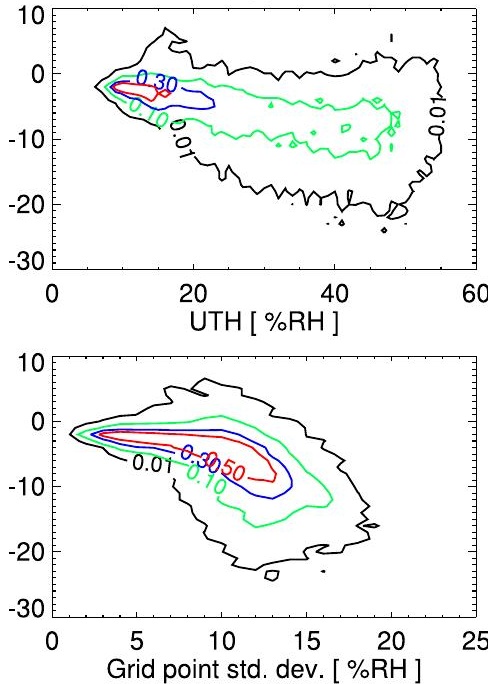


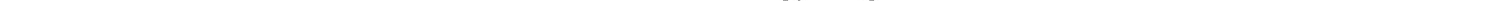

